\author{
Jordan B Minov ${ }^{1 \star}$, Jovanka \\ Karadzinska-Bislimovska ${ }^{1}$, Engin \\ Tutkun $^{2}$, Kristin Vasilevska ${ }^{3}$, Saso \\ Stoleski ${ }^{1}$ and Mijakoski $D^{1}$ \\ ${ }^{1}$ Institute for Occupational Health of R. Macedonia, \\ R. Macedonia \\ ${ }^{2}$ Ankara Occupational Diseases Hospital, Ankara, \\ Turkey \\ ${ }^{3}$ Institute for Epidemiology and Biostatistics, Skopje, \\ R. Macedonia \\ Dates: Received: 09 September, 2015; Accepted: \\ 12 January, 2016; Published: 19 January, 2016 \\ ${ }^{*}$ Corresponding author: Jordan B Minov, MD, \\ PhD, Department of Cardiorespiratory Functional \\ Diagnostics, Institute for Occupational Health of \\ R. Macedonia - WHO Collaborating Center and \\ GA2LEN Collaborating Center, II Makedonska \\ Brigada 43, 1000 Skopje, R. Macedonia, Tel: + \\ 38922639 637; Fax: + 38922621 428; E-mail: \\ minovj@hotmail.com \\ www.peertechz.com
}

Keywords: Cessation of exposure; Metacholine challenge; Non-specific bronchial hyper responsiveness; Occupation; Questionnaire; Sensitizer; Spirometry

\section{Research Article \\ Clinical and Functional Outcomes of Sensitizer-Induced Asthma in Bakers and Cotton Workers after Removal from Exposure}

\begin{abstract}
Introduction: Sensitizer-induced occupational asthma (OA) has significant health and socioeconomic outcomes in affected subjects.

Objective: To evaluate clinical and functional outcomes of sensitizer-induced OA in bakers and cotton workers three to five years after cessation of exposure to the offending workplace agent.

Methods: We studied 16 patients with sensitizer-induced OA (10 bakers and 6 textile workers), eight males and eight females, aged 32 to 48 years. All study subjects completed a questionnaire and underwent spirometric measurements and metacholine challenge, in the same manner as at the time of diagnosis. The findings obtained were compared with findings registered at the time of diagnosis.

Results: We found significantly lower prevalence of patients with respiratory symptoms in the previous 12 months after the mentioned period of removal from exposure than their prevalence at the time of diagnosis $(100 \%$ vs. $68.7 \% ; P=0.014)$. In regard to nasal symptoms, their prevalence at the time of the study was lower than at the time of diagnosis but statistical significance was not reached $(62.5 \%$ vs. $37.5 \% ; P=0.107)$. The values of spirometric parameters at the time of the study were similar to their values at the time of diagnosis. The level of the non-specific bronchial hyper responsiveness (NSBHR) at the time of the study was improved in all study subjects. The mean value of the provocative concentration $20\left(\mathrm{PC}_{20}\right)$ at the time of the study was significantly higher than its mean value registered at the time of diagnosis $(2.9$ vs. $2.1 ; P=0.032)$. However, none subject normalized his/her NSBHR.

Conclusions: Our findings indicate resolution of the respiratory and nasal symptoms in a part of the study subjects. In addition, all study subjects are left with their NSBHR, although all of them improve.
\end{abstract}

\section{Introduction}

Occupational asthma $(\mathrm{OA})$ is the most frequent occupational lung disease in the last decades, causing considerable morbidity and disability. As developed by different pathogenetic mechanisms, $\mathrm{OA}$ is distinguished in two different categories: sensitizer-induced $\mathrm{OA}$ and irritant-induced OA. Sensitizer-induced OA accounts for approximately $90 \%$ of all OA cases. Specific occupational sensitizers, i.e. the agents that induce asthma through a mechanism associated with a specific immunologic response, may be high-molecularweight (HMW) agents (proteins or glycopeptides that cause production of specific IgE antibodies and typical allergic responses) or low-molecular-weight (LMW) agents (most of which induce asthma through mechanisms that are still poorly understood). Common HMW agents are: animal allergens, plants and plant products, cereals and grains, other foods, and enzymes (workers in detergent production, pharmaceutical workers, laboratory workers, etc.). In addition, common LMW sensitizers that may induce OA are: diisocyanates, acid anhydrides, acrylic monomers, nickel and chromium salts, platinum salts, drugs, and persulfates $[1,2]$.

Existing evidence indicates that complete and definitive avoidance of exposure to the causal agent and pharmacological treatment that follows clinical-practice guidelines is the preferable approach to the management of sensitizer-induced asthma. Reduction of exposure to the causal agent may be an alternative to the complete avoidance of exposure, but it seems that reduced exposure is less beneficial than exposure cessation $[3,4]$.

According to the findings from studies on outcomes of sensitizerinduced OA after removal from the offending environment, asthma symptoms and non-specific bronchial hyperrespnsivenes (NSBHR) persist several years in majority of patients with sensitizer-induced $\mathrm{OA}$. The outcomes are best when the diagnosis is established early, the exposure is stopped, and the asthma is not yet severe $[1,5]$.

The aim of the present study was to evaluate the clinical and functional outcomes in patients with sensitizer-induced $\mathrm{OA}$ after removal from the exposure to the offending agent.

\section{Methods}

\section{Study design and setting}

The present study, performed at the Institute for Occupational 
Health of R. Macedonia, Skopje - World Health Organization (WHO) Collaborating Center and Global European Allergy and Asthma (GA $\left.{ }^{2} L E N\right)$ Collaborating Center in the period January - June 2015, is a comparison of prevalence of respiratory symptoms, spirometric parameters and NSBHR in patients with sensitizer-induced OA at the time of diagnosis and three to five years (36 to 60 months) after removal from the offending workplace exposure.

\section{Study subjects}

We studied 16 subjects with sensitizer-induced OA, 10 bakers (industrial or traditional) and six cotton workers (cotton weavers or cotton spinners), eight males and eight females, aged 32 to 48 years.

Inclusion criteria: patients with diagnosed sensitizer-induced $\mathrm{OA}$ three to five years removed from exposure to the offending occupational agent.

Exclusion criteria: patients with diagnosed sensitizer-induced OA who were not removed from the harmful workplace exposure and patients with diagnosed sensitizer-induced OA removed from exposure to the offending occupational agent for shorter or longer period.

At the time of diagnosis (2010-2012), all examined subjects were symptomatic and their asthma symptoms were work-related. The diagnostic work-up included skin prick tests (SPT) to standard inhalant and to relevant workplace allergens, spirometry, and metacholine challenge (as it was not contraindicated in any of them). The diagnosis of sensitizer-induced OA was established by finding of significant changes of the peak expiratory flow rate (PEFR) registered by serial PEFR measurements at and away from work. After the diagnosis was confirmed all examined subjects were removed from the offending occupational exposure and controller treatment with inhaled corticosteroids was initiated according to the actual recommendations and local availability of asthma medications [6]. Removal from offending occupational exposure was realized mainly by relocation in the workplace and, less commonly, by a change in occupation.

In both groups there was no subject in whom metacholine challenge was contraindicated [7,8], nor subject with upper respiratory viral infection within 3 weeks before the metacholine challenge test. All study subjects were informed about the study and their written consent was obtained.

\section{Questionnaire}

Respiratory symptoms in the previous 12 months (cough, shortness of breath, wheezing, and chest tightness) were documented using the European Community Respiratory Health Survey (ECRHS) screening questionnaire [9]. The patient was considered symptomatic if he/she had one or more respiratory symptoms in the previous 12 months.

Nasal symptoms in the previous 12 months (sneezing, itching, runny nose, blocked nose, and red, itchy eyes) were documented according to the Allergic Rhinitis and its Impact to Asthma (ARIA) Pocket Guide [10]. The patient was considered symptomatic if he/she had one or more nasal symptoms in the previous 12 months.
Detailed smoking history, family history of asthma (taking into account the first-degree relatives), accompanying disease, and medication use were also evaluated. Smoking was classified according to the WHO Guidelines for Controlling and Monitoring the Tobacco Epidemic [11]. Daily smoker was defined as a subject who smoked at the time of the survey at least once a day, except on days of religious fasting. Ex-smoker was defined as a formerly daily smoker, no longer smokes. Passive smoking or exposure to environmental tobacco smoke (ETS) was defined as an exposure to tobacco combustion products from smoking by others (at home, workplace, etc.), i.e. as a presence of at least one smoker in the household and/or in the workplace $[12,13]$.

\section{Spirometry}

The Spiro metric measurements, including measures of forced vital capacity (FVC), forced expiratory volume in one second $\left(\mathrm{FEV}_{1}\right)$, $\mathrm{FEV}_{1} / \mathrm{FVC}$ ratio, and maximal expiratory flow at $75 \%, 50 \%, 25 \%$, and $25-75 \%$ of $\mathrm{FVC}\left(\mathrm{MEF}_{75}, \mathrm{MEF}_{50}, \mathrm{MEF}_{25}\right.$, and $\mathrm{MEF}_{25-75}$, respectively), was performed in all subjects using spirometer Ganshorn Sano Scope LF8 (Ganshorn Medizin Electronic GmbH, Germany) with recording the best result from three measurements the values of $\mathrm{FEV}_{1}$ of which were within $5 \%$ of each other. The results of spirometry were expressed as percentages of the predicted values according to the actual recommendations of European Respiratory Society (ERS) and American Thoracic Society (ATS) [14,15].

\section{Metacholine challenge}

The metacholine challenge tests were performed in all subjects according to the European Respiratory Society (ERS) / American Thoracic Society (ATS) recommendations [7,8], in the same manner as at the time of diagnosis. Concentrations of $0.25,0.5,1,2,4,8$, and $16 \mathrm{mg} / \mathrm{mL}$ metacholine (Fagron $\mathrm{GmbH}$, Germany) were prepared by dilution with buffered saline. The doses of aerosol generated by Pari LC nebulizer (Pari GmbH, Germany) were inhaled through a mouthpiece. The subjects inhaled increasing concentrations of metacholine by tidal breathing method until $\mathrm{FEV}_{1}$ fell by more than $20 \%$ of its base value (provocative concentration $20-\mathrm{PC}_{20}$ ) or the highest concentration was reached. The method of calculating the $\mathrm{PC}_{20}$ is described elsewhere [16]. The logarithmic transformation of $\mathrm{PC}_{20}$ was used in the analysis.

According to the ATS recommendations bronchial hyper responsiveness (BHR) (i.e. NSBHR) was categorized as moderate to severe BHR $\left(\mathrm{PC}_{20}<1.0 \mathrm{mg} / \mathrm{mL}\right)$, mild BHR $\left(\mathrm{PC}_{20}=1.0-4.0 \mathrm{mg} / \mathrm{mL}\right)$ and borderline $\mathrm{BHR}\left(\mathrm{PC}_{20}>4.0 \mathrm{mg} / \mathrm{mL}\right)$. The test was considered positive if $\mathrm{PC}_{20}$ was equal or less than $4 \mathrm{mg} / \mathrm{mL}$ (8). Significant improvement of the NSBHR was considered in the patients with twofold increase of the $\mathrm{PC}_{20}$ as compared to its value at the time of diagnosis.

\section{Statistical analysys}

Continuous variables were expressed as mean values with standard deviation (SD), whereas the nominal variables as numbers and percentages. A chi-square test (or Fisher's exact test where appropriate) was used for testing difference in the prevalence. Comparison of the mean values was performed by an independent- 
samples $t$-test. Relation between changes in respiratory symptoms and increase of the $\mathrm{PC}_{20}$ was tested by a chi-square test. A $P$-value less than 0.05 was considered as statistically significant. Statistical analysis was performed using the Statistical Package for the Social Sciences (SPSS) version 11.0 for Windows.

\section{Results}

Demographic characteristics of the examined subjects are shown on Table 1.

At the time of diagnosis, all study subjects reported respiratory symptoms in the previous 12 months. In addition, $62.5 \%$ of them reported nasal symptoms in the previous 12 months. All study subjects with respiratory and nasal symptoms reported work-relatedness of their symptoms (i.e. worsening of the symptoms during working days and their improvement during weekends, holidays and vacations). Metacholine challenge test was positive in all examined subjects. According to the $\mathrm{PC}_{20}$ value, the NSBHR in three patients (patient 8,10 and 15) was categorized as severe to moderate, while in other patients the NSBHR was categorized as mild (Table 2).

SPT to one or more standard inhalant allergens were positive in all examined subjects. All bakers had positive SPT to wheat and two of them besides being positive to wheat also had positive SPT to meal, whereas all textile workers had positive SPT to cotton.

The prevalence of patients with respiratory symptoms in the previous 12 months at the time of the study was significantly lower than their prevalence at the time of diagnosis of sensitizer-induced OA, i.e. at the time of study symptomatic was around two thirds of them $(100 \%$ vs. $68.7 \% ; P=0.014)$. The prevalence of patients with nasal symptoms at the time of the study was also lower than their initial prevalence but the difference was not statistically significant (62.5\% vs. $37.5 \% ; P=0.107$ ). The values of spirometric parameters $\left(\mathrm{FEV}_{1}\right.$ and $\left.\mathrm{FEV}_{1} / \mathrm{FVC}\right)$ at the time of the study were similar to their values registered at the time of diagnosis. As at the time of diagnosis, at the time of the study all study subjects had positive metacholine challenge test. The values of the $\mathrm{PC}_{20}$ in all study subjects were higher than their values at the time of diagnosis, i.e. at the time of the study the NSBHR in all study subjects, except in the patient 15 , was categorized as mild. Significant improvement of the NSBHR was registered in four patients (patient 4, 8, 14 and 15). The mean $\mathrm{PC}_{20}$ value was significantly higher than its mean value at the time of diagnosis (2.9 vs. 2.1; $P=0.032$ ) (Table 3 ).

We did not any relationship between the presence of respiratory symptoms in the previous 12 months and the period since removal from the exposure less or more than 48 months (improvement as opposed to no change). There was either no significant association between increase of the $\mathrm{PC}_{20}$ and the period of removal from the exposure less or more than 48 months (significant as opposite to nonsignificant increase of the $\mathrm{PC}_{20}$ ).

\section{Discussion}

As it is mentioned above, $\mathrm{OA}$ is the most common occupational lung disease in industrialized countries and despite intensive preventive measures there is little evidence that its overall incidence is declining [17]. More than $90 \%$ of all OA cases develop as a consequence of allergic sensitization to HMW and LMW present at the workplace. Existing evidence indicate that more than 250 sensitizing agents was recognized as causing asthma through different immunologic mechanisms [18]. The high-risk occupations and industries associated with the development of sensitizerinduced OA vary depending on the dominant industrial sectors in a particular country. According to the results of the populationbased study carried out by Kogevinas et al. [19], which included more than 15.000 people randomly selected from general population of 12 industrialized countries aged 20 to 44 years, the highest risk for OA was found for farmers, painters, plastic workers, cleaners, spray painters, and agricultural workers. Baker's asthma is one of the leading causes of sensitizer-induced OA worldwide [20,21]. The disease is caused by inhalation of cereal flour allergens, enzymes and storage proteins, particularly wheat flour allergens [22]. It is also well

\begin{tabular}{|c|c|c|c|c|c|c|}
\hline Pt. & Sex & Age (yr) & Workplace & Smoking status & $\begin{array}{l}\text { Exposure } \\
\text { to ETS }\end{array}$ & Duration of employment at the actual workplace (yr) \\
\hline 1 & M & 28 & Industrial baker & DS & + & 2 \\
\hline 3 & $\mathrm{~F}$ & 38 & Traditional baker & NS & - & 7 \\
\hline 4 & M & 34 & Industrial baker & NS & + & 3 \\
\hline 5 & $\mathrm{~F}$ & 40 & Industrial baker & DS & - & 4 \\
\hline 6 & M & 30 & Industrial baker & NS & - & 3 \\
\hline 8 & $\mathrm{~F}$ & 43 & Industrial baker & DS & + & 7 \\
\hline 9 & M & 33 & Industrial baker & DS & - & 3 \\
\hline 10 & M & 29 & Traditional baker & ES & - & 3 \\
\hline 11 & $\mathrm{~F}$ & 42 & Cotton spinner & DS & - & 6 \\
\hline 12 & M & 34 & Cotton weaver & ES & - & 3 \\
\hline 13 & $\mathrm{~F}$ & 29 & Cotton spinner & NS & + & 3 \\
\hline 14 & $\mathrm{~F}$ & 38 & Cotton spinner & NS & + & 7 \\
\hline 15 & $\mathrm{~F}$ & 44 & Cotton weaver & DS & - & 8 \\
\hline Mean & & 35.6 & & & & 4.4 \\
\hline SD & & 5.4 & & & & 1.9 \\
\hline
\end{tabular}

Pt: Patient; Yr: Year; M: Male; F: Female; DS: Daily S; NS: Non Smoker; ES: Ex-Smoker; ETS: Environmental Tobacco Smoke; SD: Standard Deviation. 


\begin{tabular}{|c|c|c|c|c|c|c|c|}
\hline Pt. & Respiratory symptoms & Nasal symptoms & $\begin{array}{l}\text { Duration of } \\
\text { respiratory symptoms } \\
\text { (mo) }\end{array}$ & $\begin{array}{l}\text { FEV1 } \\
\text { (\%pred) }\end{array}$ & FEV1/FVC & $\begin{array}{l}\text { PC20 } \\
\text { (mg/mL) }\end{array}$ & $\begin{array}{l}\text { Asthma controller } \\
\text { Daily dose } \\
(\mu \mathrm{g})\end{array}$ \\
\hline 2 & + & + & 18 & $83 \%$ & 0.77 & 3.1 & Fluticasone propionate 250 \\
\hline 3 & + & + & 9 & $87 \%$ & 0.82 & 3.4 & Fluticasone propionate 250 \\
\hline 4 & + & + & 12 & $79 \%$ & 0.75 & 1.2 & Fluticasone propionate 500 \\
\hline 5 & + & - & 10 & $84 \%$ & 0.80 & 3.3 & Fluticasone propionate 250 \\
\hline 7 & + & - & 22 & $74 \%$ & 0.74 & 1.4 & Fluticasone/Salmeterol $250 / 50$ \\
\hline 8 & + & - & 14 & $76 \%$ & 0.77 & 0.7 & Fluticasone/Salmeterol 500/50 \\
\hline 9 & + & + & 8 & $84 \%$ & 0.81 & 2.5 & Fluticasone propionate 250 \\
\hline 10 & + & - & 12 & $89 \%$ & 0.74 & 0.8 & Fluticasone propionate 750 \\
\hline 11 & + & + & 24 & $73 \%$ & 0.76 & 1.6 & Fluticasone propionate 500 \\
\hline 12 & + & + & 18 & $90 \%$ & 0.81 & 3.7 & Fluticasone propionate 250 \\
\hline 13 & + & - & 9 & $87 \%$ & 0.80 & 2.7 & Fluticasone propionate 250 \\
\hline 14 & + & - & 15 & $76 \%$ & 0.78 & 1.2 & Fluticasone propionate 500 \\
\hline 16 & + & + & 10 & $83 \%$ & 0.76 & 3.2 & Fluticasone propionate 250 \\
\hline Mean & & & 13.8 & 82.7 & 0.78 & 2.1 & \\
\hline SD & & & 5.1 & 6.6 & 0.03 & 1.1 & \\
\hline
\end{tabular}

Pt: Patient; Mo: Month; FEV1: Forced Expiratory Volume in one second; Pred\%: \% of Predicted value; FVC: Forced Vital Capacity; PC20: Provocative Concentration 20; mg: milligram; mL: milliliter; $\mu \mathrm{g}$ : microgram; SD: Standard Deviation.

\begin{tabular}{|c|c|c|c|c|c|c|c|}
\hline Pt. & $\begin{array}{l}\text { Respiratory } \\
\text { symptoms }\end{array}$ & $\begin{array}{l}\text { Rhinitis } \\
\text { symptoms }\end{array}$ & $\begin{array}{l}\text { Period since removal from } \\
\text { exposure }(\mathrm{mo})\end{array}$ & $\begin{array}{l}\text { FEV1 } \\
\text { (\%pred) }\end{array}$ & FEV1/FVC & $\begin{array}{l}\text { PC20 } \\
(\mathrm{mg} / \mathrm{mL})\end{array}$ & $\begin{array}{l}\text { Asthma controller } \\
\text { Daily dose } \\
(\mu \mathrm{g})\end{array}$ \\
\hline 1 & + & - & 42 & $86 \%$ & 0.77 & 2.9 & Fluticasone propionate 250 \\
\hline 2 & - & - & 55 & $81 \%$ & 0.78 & 3.8 & Fluticasone propionate 250 \\
\hline 3 & + & - & 38 & $91 \%$ & 0.84 & 3.7 & Fluticasone propionate 250 \\
\hline 4 & + & + & 43 & $77 \%$ & 0.74 & 2.8 & Fluticasone/Salmeterol $250 / 50$ \\
\hline 6 & + & + & 48 & $93 \%$ & 0.82 & 2.9 & Fluticasone propionate 250 \\
\hline 7 & - & - & 46 & $72 \%$ & 0.73 & 2.1 & Fluticasone/Salmeterol $250 / 50$ \\
\hline 8 & + & - & 60 & $78 \%$ & 0.78 & 1.7 & Fluticasone/Salmeterol $250 / 50$ \\
\hline 9 & - & + & 42 & $83 \%$ & 0.79 & 2.8 & Fluticasone propionate 250 \\
\hline 10 & + & - & 57 & $86 \%$ & 0.73 & 1.2 & Fluticasone/Salmeterol 250/50 \\
\hline 11 & + & + & 51 & $75 \%$ & 0.78 & 1.8 & Fluticasone/Salmeterol $500 / 50$ \\
\hline 12 & + & + & 58 & $88 \%$ & 0.78 & 3.8 & Fluticasone propionate 250 \\
\hline 13 & - & - & 44 & $89 \%$ & 0.83 & 3.1 & Fluticasone/Salmeterol $500 / 50$ \\
\hline 15 & + & - & 57 & $72 \%$ & 0.74 & 0.9 & Fluticasone/Salmeterol $250 / 50$ \\
\hline 16 & + & + & 39 & $81 \%$ & 0.76 & 3.5 & Fluticasone propionate 250 \\
\hline Mean & & & 48.5 & 82.1 & 0.77 & 2.9 & \\
\hline SD & & & 7.2 & 6.5 & 0.04 & 0.9 & \\
\hline
\end{tabular}

established that occupational exposure in textile industry increases risks of chronic nonspecific lung disease including sensitizer-induced OA [23]. According to the findings of the study on distribution of sensitizer-induced OA in R. Macedonia in the period 2005-2014 by occupation, baker's asthma and sensitizer-induced OA in cleaners and textile workers were the three most common types accounting for more than $30 \%$ of all sensitizer-induced OA cases [24]

Existing evidence about clinical outcomes after establishing the diagnosis of sensitizer-induced OA produces somewhat inconsistent results [25]. In addition, besides its health implications, diagnosis of sensitizer-induced $\mathrm{OA}$ is related with serious socioeconomic implications. Namely, cessation of exposure to offending occupational agent usually is associated with a decrease in asthma severity and in pharmaceutical expenses, but it is often associated with a deterioration of patient's socioeconomic status (professional downgrading and loss of work-derived income) $[26,27]$.

In the present study we investigated clinical and functional outcomes (respiratory symptoms in the previous 12 months, lung function, and NSBHR) of sensitizer-induced asthma in bakers and cotton workers after removal from exposure to the offending agent. None of the study subjects had neither childhood asthma, nor asthma before the entering the certain workplace. The mean duration of employment at the time of diagnosis in these workers was 4.4 years. At the time of diagnosis all examined subjects were symptomatic (i.e. 
had one or more respiratory symptoms in the previous 12 months). In addition, around two third of them also had one or more rhinitis symptoms. The mean duration of respiratory symptoms before the diagnosis was established was around 14 months. Sensitizer-induced $\mathrm{OA}$ is characterized by a variable time during which sensitization takes a place and is usually caused by only one agent [18]. Existing evidence indicates that in approximately a half of the sensitizerinduced OA cases the disease develops in the first two years of the exposure to offending workplace agent [28]. At the time of diagnosis, the spirometric parameters of the study were in the range of their referent values. Metacholine challenge test was positive in all study subjects, being categorized as severe to moderate in four of them. The diagnosis of sensitizer-induced asthma was established by positive results of serial PEFR measurements. After the diagnosis was established, all study subjects were removed from their workplaces and appropriate treatment was initiated.

The findings from several studies indicated that majority of patients with sensitizer-induced asthma did not recover, even after several years away from offending exposure and that they may have permanent impairment and disability $[25,29,30]$. The duration of symptoms, the severity of NSBHR at the time of diagnosis, the total duration of exposure to the offending workplace agent and its duration afte the onset of symptoms are important determinants of outcome [31]. According to the findings from study conducted by Perfetti et al., longer duration of the interval from cessation of exposure appears to be an important factor in improving the outcome and that current or past use of inhaled corticosteroids is not a significant predictor for explaining different outcomes in workers removed from offending exposure [32]). In addition, findings from the double- blind study conducted by Malo et al., indicated that inhaled corticosteroids induce a small but important overall improvement in patients with sensitizer-induced OA [33]. On the other hand, the studies that examined the changes in NSBHR and changes in specific bronchial responsiveness (evaluated by specific inhalation challenge) did not find any correlation between these two factors, i.e. registered significant improvement in specific bronchial hyper responsiveness was not accompanied by significant improvement in NSBHR $[29,34,35]$.

In the present study the mean duration of the interval since removal from exposure to the offending workplace agent to the second metacholine challenge test was around 48 months. In this period, the recommended pharmacological treatment was used by all study subjects. At the time of the study, we registered improvement in the clinical and functional parameters of the study subjects. Around $30 \%$ of the study subjects at this time was asymptomatic, i.e. did not report any respiratory symptom in the previous 12 months. An improvement of the prevalence of nasal symptoms was also registered. We did not perform SPT at the time of the study, so eventual immunological changes in the study subjects could not be documented. The values of spirometric parameters were similar as compared to their values registered at the time of diagnosis. At the time of the study, we registered improvement in the NCBHR level in all study subjects. Furthermore, the NCBHR level in four study subjects was significantly lower than its level registered at the time of diagnosis. However, although the NSBHR level was improved in all study subjects, it was not normalized in none of them (i.e. none study subject had a complete loss of the NSBHR). The studies on clinical and functional outcome of sensitizer-induced OA caused by specific workplace sensitizers produced different results. In workers with sensitizer-induced asthma due to isocyanates, Mapp et al. found that NSBHR (evaluated by metacholine challenge) decreased slowly and gradually and continued after 96 months from the cessation of exposure [36]. In addition, in the study including patients with sensitizer-induced asthma due to tetrachlorphtalic anhydride, Barker et al. found persistent symptoms and NSBHR level despite avoidance of exposure for 12 years [37]. In the present study we did not register significant association neither between the presences of respiratory symptoms in the previous 12 months, nor between the improvement of the NSBHR and duration of the period since removal from the offending exposure.

The present study has some limitations. First, relatively small number of the study subjects could have certain implications on the data obtained and its interpretation. Second, relatively short period of the removal from the exposure to offending agent could also have certain implications of the data obtained and its interpretation. Third, although the study subjects worked at similar workplaces, their work environments at the time of diagnosis, as well as at the time of the second NSBHR, were different, that may have significant impact on our findings. The strength of the study is the comparison of clinical and functional features of sensitizer-induced OA developed at the specific workplaces after removal from the offending exposure.

\section{Conclusions}

In conclusion, in a study aimed at evaluation of respiratory symptoms, lung function and NSBHR in bakers and cotton workers with sensitizer-induced $\mathrm{OA}$ three to five years after removal from the offending workplace exposure, we found a lower prevalence of respiratory and nasal symptoms in the previous 12 months, similar values of spirometric parameters, and a decrease in the level of NSBHR than at the time of diagnosis. Our findings also indicate a need of further investigations in this field in order to improve the understanding of the course of sensitizer-induced OA and to improve the management of these patients.

\section{Authors Participations}

JM participated in the study design, writing the protocol, data collection, managing the analyses of the study, and writing all versions of the manuscript. JKB participated in the study design, writing the protocol, managing the analyses of the study, as well as writing all versions of the manuscript. ET participated in the managing the analyses of the study and in the writing all versions of the manuscript. $\mathrm{KV}$ performed the statistical analysis and participated in the managing of the analyses of the study. SS and DM participated in the data collection and in the managing of the analyses of the study. All authors read and approved the final manuscript.

\section{References}

1. Tarlo SM, Lemiere C (2014) Occupational asthma. N Engl J Med 370: 640649.

2. Lombardo LJ, Balmes JR (2000) Occupational asthma: A review Perspect 108: $687-704$. 
3. de Groene GJ1, Pal TM, Beach J, Tarlo SM, Spreeuwers D, et al. (2011) Workplace intervention for treatment of occupational asthma. Cochrane Database Syst Rev 5: CD006308.

4. Vandenplas O, Dressel H, Nowak D, Jamart J (2012) What id the optimal management option for occupational asthma? Eur Respir Rev 21: 97-104.

5. Beach J, Rowe BH, Blitz S, Crumley E, Hooton N, et al. (2005) Diagnosis and management of work-related asthma. Evid Rep Technol Assesss (Summ) 129: $1-8$.

6. (2015) Global Strategy for Asthma Management and Prevention 2010 (update).

7. P.J. Sterk, L.M. Fabbri, Ph.H. Quanjer, D.W. Cockcroft, P.M. O’Byrne, et al. (1993) Airways Responsiveness. Standardized challenge testing with pharmacological, physical and sensitizing stimuli in adults. Report Working Party for the Standardization of Lung Function Tests. European Community for Steel and Coal. Official Statement of the European Respiratory Society. Eur Respir 6: 58-83.

8. Crapo RO, Casaburi R, Coates AL, Enright PL, Hankinson JL, et al. American Thoracic Society (2000) Guidelines for Metacholine and Exercise Challenge Testing -1999. Am Respir Crit Care Med 161: 309-329.

9. European Community Respiratory Health Survey (1996) Variations in the prevalence of respiratory symptoms, self-reported asthma attacks, and use of asthma medication in the European Respiratory Health Survey (ECRHS) Eur Respir J 9: 687-695.

10. ARIA Pocket Guide (2015) Management of Allergic Rhinitis and its Impact to Asthma. 1-8.

11. World Health Organization (1998) Guidelines for controlling and monitoring the tobbaco epidemic. Geneva: WHO, 1998

12. U.S. Department of Health and Human Services (1984) The health consequences of smoking: chronic obstructive pulmonary disease. A report of the Surgeon General. US Department of Health and Human Services Public Health Service, Office of the Assistant for Health, Office of Smoking and Health. DHHS Publication No. 84-50 205.

13. Janson C1, Chinn S, Jarvis D, Zock JP, Torén K, et al. (2001) Effects of passive smoking on respiratory symptoms, bronchial responsiveness, lung function, and total serum IgE in the European Community Respiratory Health Survey: a cross-sectional study. Lancet 358: 2103-2109.

14. Spirometry Guide: 2010 Update.

15. Miller MR1, Hankinson J, Brusasco V, Burgos F, Casaburi R, et al. (2005) Standardisation of spirometry. Eur Respir J 26: 319-338.

16. Cockroft DW, Murdock KY, Mink JT (1983) Determination of histamine PC20. Comparison of linear and logarithmic interpolation. Chest 84: 505-506.

17. McDonald JC, Chen Y, Zekveld C, Cherry NM (2005) Incidence by occupation and industry of acute work related respiratory disease in the UK, 1992-2001. Occup Environ Med 62: 836-842.

18. Mapp CE, Saetta M, Maestrelli P, Fabbri L (1999) Occupational asthma. Eur Respir Mon 11: 255-285.

19. Kogevinas M1, Antó JM, Sunyer J, Tobias A, Kromhout H, et al. (1999) Occupational asthma in Europe and other industrialised areas: a populationbased study. European Community Respiratory Health Survey Study Group. Lancet 353: 1750-1754.

20. Baur X, Degens PO, Sander I (1998) Baker's asthma: still among the most frequent occupational respiratory disorders. J Allergy Clin Immunol 102: 984 997.

21. Brant A (2007) Baker's asthma. Curr Opin Allergy Clin Immunol 7: 152-155.

22. Salcedo G, Quirce S, Diaz-Perales A (2011) Wheat allergens associated with baker's asthma. I Investig Allergol Clin Immunol 21: 81-92.

23. Heederik D, Kromhout H, Burema J, et al. (1990) Occupational exposure and 25-year incidence rate of nonspecific lung disease: the Zutphen Study. Int J Epidemiol 1990; 19: 945-952.

24. Minov J, Karadzinska-Bislimovska J, Vasilevska K, et al. (2005) Distribution of sensitizer-induced occupational asthma in R. Macedonia in the period 2005-2014 by occupation. Glob J Allergy 1: 19-23.

25. Rachiotis G, Savani R, Brant A, MacNeill SJ, Newman Taylor A, et al. (2007) Outcome of occupational asthma after cessation of exposure: a systematic review. Thorax 62: 147-152.

26. Ross DJ, McDonald JC (1998) Health and employment after a diagnosis of occupational asthma: a descriptive study. Occup Med 4: 219-225.

27. Moscato G, Dellabianca A, Perfetti L, Bramè B, Galdi E, et al. (1999) Occupational asthma. A longitudinal study on the clinical and socioeconomic outcome after diagnosis. Chest 115: 249-256.

28. Malo JL, Cartier A (1996) Occupational asthma. In: Harber P, Schenker MB Balmes JR, eds. Occupational and Environmental Respiratory Disease. St. Louis: Mosby 420-432.

29. Lemière C, Cartier A, Dolovich J, Chan-Yeung M, Grammer L, et al. (1996) Outcome of specific bronchial responsiveness to occupational agents after removal from exposure. Am J Respir Crit Care Med 154: 329-333.

30. Lin FJ, Dimich Ward H, Chan-Yeung M (1996) Longitudinal decline in lung function in patients with occupational asthma due to western red cedar. Occup environ Med 53: 753-756.

31. Siracusa A, Kennedy SM, DyBuncio A, Lin FJ, Marabini A, et al. (1995) Prevalence and predictors of asthma in working groups in British Columbia. Am J Ind Med 28: 411-423.

32. Perfetti L, Cartier A, Ghezzo H, Gautrin D, Malo JL (1998) Follow up of occupational asthma after removal from or diminution of exposure to the responsible agent. Chest 114: 398-403.

33. Malo JL, Cartier A, Côté J, Milot J, Leblanc C, et al. (1996) Influence of inhaled steroids on recovery from recovery of occupational asthma after cessation of exposure: an 18-month double-blind crossover study. Am J Respir Crit Care Med 153: 953-960.

34. Merget R1, Reineke M, Rueckmann A, Bergmann EM, Schultze-Werninghaus G (1994) Nonspecific and specific bronchial responsiveness in occupational asthma caused by platinum salts after allergen avoidance. Am J Respir Crit Care Med 150: 1146-1149.

35. Saetta M1, Maestrelli P, Turato G, Mapp CE, Milani G, et al. (1995) Airway wall remodeling after cessation of exposure to isocyanates in sensitized asthmatic subjects. Am J Respir Crit Care Med 151: 489-494.

36. Mapp C, Saetta M, Maestrelli P (1998) Outcome of nonspecific airway responsiveness to metacholine in isocyanate induced asthma. Eur Respir $J$ 12: $17-18$.

37. Barker RD, Harris JM, Welch JA, Venables KM, Newman Taylor AJ (1998) Occupational asthma caused by tetrachlorphtalic anhydride: a 12-year follow up. J Allergy Clin Immunol 101: 717-719.

Copyright: (C) 2016 Minov JB, et al. This is an open-access article distributed under the terms of the Creative Commons Attribution License, which permits unrestricted use, distribution, and reproduction in any medium, provided the original author and source are credited. 